\title{
Perbandingan Metode Kalibrasi dan Adisi Standar untuk Penentuan Timbal Terlarut dalam Air Bak Kontrol Candi Borobudur Secara Spektrofotometri Serapan Atom (SSA)-Nyala
}

\author{
Ida Sulistyaningrum, Melati Putri Git Utami, Reni Banowati Istiningrum \\ D III Analis Kimia Universitas Islam Indonesia Yogyakarta \\ Email: ida.sulistyaningrum@ymail.com
}

\begin{abstract}
Abstrak: Telah dilakukan perbandingan metode kalibrasi dan adisi standar untuk penentuan timbal terlarut dalam sampel air bak kontrol Candi Borobudur. Studi dilakukan untuk mengembangkan metode adisi standar dalam penentuan kadar timbal terlarut yang sangat rendah menggunakan Spektrofotometri Serapan Atom (SSA)-Nyala. Pengambilan sampel dilakukan di lima titik, yaitu satu titik sisi selatan, satu titik sisi barat daya, dan tiga titik sisi utara Candi Borobudur. Metode adisi standar memiliki sensitivitas metode yang lebih baik daripada kalibrasi standar. Linearitas (R) kurva kalibrasi yang diperoleh sebesar 0,957, sementara linearitas kurva adisi standar $\geq 0,995$ (kecuali sampel kode AS). Kedua metode memberikan kadar timbal terlarut yang berbeda dengan hasil metode kalibrasi lebih besar daripada hasil metode adisi standar.
\end{abstract}

Kata Kunci: timbal terlarut, air bak kontrol, Candi Borobudur, metode kalibrasi, metode adisi standar

\begin{abstract}
Calibration and standard addition method of dissolved lead determined in Borobudur's control tanks water were compared. The aim of the study was to develop standard addition method to determine dissolved lead in a very low concentration using Flame Absorbtion Spectrophotometry (F-AAS). Samples were taken from five places: a point at south side, a point at south west, and three points at north of Borobudur Temple. Linearity of both curved were compared. The linearity of calibration curved was 0,957092, while standard addition had linearity $\geq 0,995$ (except sample AS). Both method gave different dissolved lead concentration. The result of calibration method was higher than standard addition method.
\end{abstract}

Keywords: dissolved lead, control tanks water, Borobudur Temple, calibration method, standard addition method

\section{Latar Belakang}

Candi Borobudur merupakan salah satu peninggalan umat Buddha yang menjadi ikon Indonesia. Dalam perjalanan sejarahnya, Candi Borobudur telah mengalami dua kali pemugaran yang dilakukan untuk menangani kerusakan candi akibat beberapa faktor, antara lain korosi, efek kerja mekanis, serta kekuatan tekanan dan tegangan dalam batu-batu candi (Soekmono, 1983). Hal ini tidak terlepas dari masalah sistem pembuangan air dan rembesan air ke permukaan batuan, mengingat letak geografis Candi Borobudur yang beriklim basah dengan curah hujan yang tinggi (Winarno, 1995). Salah satu upaya untuk mengatasi masalah tersebut adalah dengan penggunaan lapisan timbal pada lapisan kedap air di bawah reliefrelief setinggi lorong untuk mencegah perembesan air ke permukaan batuan (Soekmono, 1983). Sifat timbal yang lunak dan antikorosi menyebabkan timbal digunakan sebagai pelapis.

Penggunaan timbal dalam konstruksi Candi Borobudur berpotensi menimbulkan pencemaran. Timbal mudah larut dalam air yang bersifat asam, terutama oleh adanya HNO3. Air hujan yang bersifat asam dapat meresap dan terakumulasi pada lapisan timbal. Kontak langsung yang lama antara air hujan dan lapisan timbal dapat menyebabkan pelarutan lapisan timbal membentuk $\mathrm{Pb}(\mathrm{NO} 3) 2$. Timbal terlarut ini dapat terbawa aliran air dan masuk ke sistem saluran air yang berakhir di bak kontrol sebelum dibuang ke lingkungan.

Metode utama penentuan kadar timbal terlarut dalam air bak kontrol secara Spektrofotometri Serapan Atom (SSA)-Nyala di Balai Konservasi Borobudur adalah metode kalibrasi. Spektrofotometer serapan atom (SSA)-Nyala sendiri memiliki kelemahan untuk mendeteksi kadar timbal yang rendah, sehingga penggunaan metode kurva kalibrasi tidak mampu meningkatkan sensitivitas metode. Oleh karena itu, pengembangan metode adisi standar perlu dilakukan dan diharapkan mampu meningkatkan sensitivitas metode.

Studi ini dilakukan untuk membanding-kan sensitivitas metode, linearitas dan kadar $\mathrm{Pb}$ terlarut yang dihasilkan dari metode adisi standar dengan 
metode kalibrasi. Sensitivitas metode dapat diketahui dari kemiringan (slope) kurva kalibrasi dan kurva adisi standar. Sementara itu, linearitas ditentukan dari nilai korelasi regresi linear yang mengacu pada SNI 6989.8-2009, yaitu $R \geq 0,995$.

\section{Metodologi}

Kadar timbal terlarut dalam sampel air bak kontrol Candi Borobudur diuji dengan dua metode yang berbeda. Metode yang digunakan adalah metode kurva kalibrasi dan metode adisi standar dengan pengujian yang dilakukan di Laboratorium Kimia Balai Konservasi. Adapun bahan, peralatan dan cara kerja pengujian diuraikan di bawah ini.

\section{Bahan}

Bahan-bahan yang digunakan meliputi sampel air bak kontrol Candi Borobudur, Titrisol Pb 1000 mg (Merck) untuk membuat larutan standar kalibrasi dan larutan standar adisi timbal, akuabides (PT Ikapharmindo Putramas) sebagai pelarut, dan HNO3 (70,5\%; @ 1,42 g/mL, Merck) untuk mengawetkan sampel.

\section{Alat}

Peralatan pengambilan sampel air bak kontrol antara lain timba plastik $1 \mathrm{~L}$, botol sampel $1 \mathrm{~L}$, dan waterproof portable meter (Eutech Instruments CyberScan PC 650). Pengujian kadar timbal terlarut secara metode kalibrasi dan adisi standar menggunakan Spektrofotometer Serapan Atom (SSA)-Nyala (Analytik Jena novAA 350).

\section{Cara Kerja}

\section{a. Pengambilan dan Preparasi Sampel}

Pengambilan sampel air bak kontrol dilakukan pada Bulan Februari 2014 di lima bak kontrol Candi Borobudur menggunakan timba. Sampel air bak kontrol diambil dari lima titik, yaitu satu titik di sisi selatan (S), satu titik di sisi barat daya (BD), dan tiga titik di sisi utara (U1, U2, U3). Kualitas sampel diuji menggunakan waterproof portable meter dengan parameter keasaman $(\mathrm{pH})$, temperatur, total padatan terlarut (TDS), salinitas $(\mathrm{NaCl})$, dan konduktivitas.

Sampel disaring dengan saringan berpori 0,45 $\mu \mathrm{m}$ untuk menghilangkan padatan tersuspensi dan koloid. Selanjutnya, sampel diasamkan dengan
HNO3 pekat hingga $\mathrm{pH}<2$ sesuai SNI 6989.8-2009. Pengsaman ini yang mampu mengawetkan sampel hingga 6 bulan pada temperatur ruang.

\section{b. Penentuan kadar $\mathrm{Pb}$ terlarut secara kurva kalibrasi}

Larutan standar $\mathrm{Pb}$ dibuat dari larutan baku $\mathrm{Pb} 10$ $\mathrm{mg} / \mathrm{L}$ yang berasal dari Titrisol Pb. Seri larutan standar timbal yang digunakan adalah 0,$0 ; 0,1 ; 0,2 ; 0,4 ; 0,6$; dan 0,8 mg/L. Absorbansi larutan standar kalibrasi Pb dan sampel diukur menggunakan SSA-Nyala Analytik Jena novAA 350 pada panjang gelombang spesifik dari Hollow Cathode Lamp HCL Pb 283,3 nm.

\section{c. Penentuan kadar $\mathrm{Pb}$ terlarut sesuai metode adisi standar}

Larutan adisi standar $\mathrm{Pb}$ dibuat dalam $100 \mathrm{~mL}$ dengan cara menambahkan masing-masing $10 \mathrm{~mL}$ sampel ke dalam 0; 1; 2; 4; 6; dan 8 mL larutan $\mathrm{Pb} 10$ $\mathrm{mg} / \mathrm{L}$. Larutan standar adisi $\mathrm{Pb}$ diukur absorbansinya menggunakan SSA-Nyala Analytik Jena novAA 350 pada panjang gelombang 283,3.

\section{Pembahasan}

\section{Pengambilan dan Preparasi Sampel}

Pemeriksaan parameter timbal terlarut dilakukan selama musim penghujan. Hal ini bertujuan mengetahui adanya pelarutan lapisan timbal dalam air hujan yang bersifat asam (Winarno, 1995). Hasil pengujian kualitas sampel air bak kontrol disajikan dalam Tabel 1. Berdasarkan baku mutu sesuai KEPMENLH 51/1995 dan KEPMENKLH 02/1988, hasil pengukuran $\mathrm{pH}$, temperatur, total padatan terlarut, dan daya hantar listrik dari kelima sampel telah memenuhi baku mutu tersebut.

Gambar 1 menunjukkan hubungan antara TDS dan salinitas sampel air. Sampel air yang memiliki kandungan TDS tinggi juga mengandung salinitas yang tinggi. Sesuai Gambar 1, garam $\mathrm{NaCl}$ merupakan komponen utama TDS dalam sampel air. Sisanya berupa garam anorganik terlarut lainnya, seperti garam-garam klorida, karbonat, dan sulfat dari amonium, kalsium dan magnesium. Menurut Winarno (1995), unsur kalsium, magnesium, dan natrium berasal dari pelapukan batuan, sedangkan ion karbonat, klorida, dan sulfat dapat berasal dari 
Tabel 1. Hasil Pengujian Kualitas Sampel

\begin{tabular}{|c|c|c|c|c|c|c|c|c|c|}
\hline \multicolumn{2}{|c|}{ Parameter } & Baku Mutu & Satuan & Keterangan & \multicolumn{5}{|c|}{ Kode Sampel } \\
\hline & & & & & S & $\mathrm{BD}$ & U1 & U2 & U3 \\
\hline \multicolumn{2}{|c|}{$\mathrm{pH}$} & $6-9$ & & $\begin{array}{c}\text { KEPMENLH } \\
51 / 1995\end{array}$ & 7,08 & 6,97 & 7,19 & 7,22 & 7,48 \\
\hline \multicolumn{2}{|c|}{$\mathrm{T}$} & $\leq 38$ & ${ }^{\circ} \mathrm{C}$ & & 28 & 28 & 28 & 28 & 28 \\
\hline \multicolumn{2}{|c|}{ TDS } & 2000 & ppm & & 93,86 & 96,37 & 81,87 & 104,4 & 67,72 \\
\hline \multicolumn{2}{|c|}{$\mathrm{NaCl}$} & & ppm & & 91,79 & 94,3 & 80,68 & 101,6 & 67,69 \\
\hline \multicolumn{2}{|c|}{$\mathrm{DHL}$} & $1750-2250$ & $\mu \mathrm{S} / \mathrm{cm}$ & $\begin{array}{c}\text { KEPMENKLH } \\
2 / 1988\end{array}$ & 100,8 & 103,4 & 87,88 & 112 & 72,72 \\
\hline $\begin{array}{l}\mathrm{pH} \\
\mathrm{T} \\
\mathrm{TDS} \\
\mathrm{NaCl} \\
\mathrm{DHL}\end{array}$ & $\begin{array}{l}: \text { kea } \\
: \text { tem } \\
: \text { tota } \\
: \text { sali } \\
\text { : day }\end{array}$ & $\begin{array}{l}\text { aman } \\
\text { eratur } \\
\text { dissolved solid } \\
\text { tas sebagai ka } \\
\text { hantar listrik }\end{array}$ & $\begin{array}{l}\text { otal pada } \\
\text { ir natrium }\end{array}$ & $\begin{array}{l}\text { n terlarut) } \\
\text { lorida }\end{array}$ & $\begin{array}{l}\text { S } \\
\text { BD } \\
\text { U1 } \\
\text { U2 } \\
\text { U3 }\end{array}$ & \multicolumn{2}{|c|}{$\begin{array}{l}\text { : Titik Utara } 1 \\
: \text { Titik Utara } 2 \\
: \text { Titik Utara } 3\end{array}$} & & \\
\hline
\end{tabular}

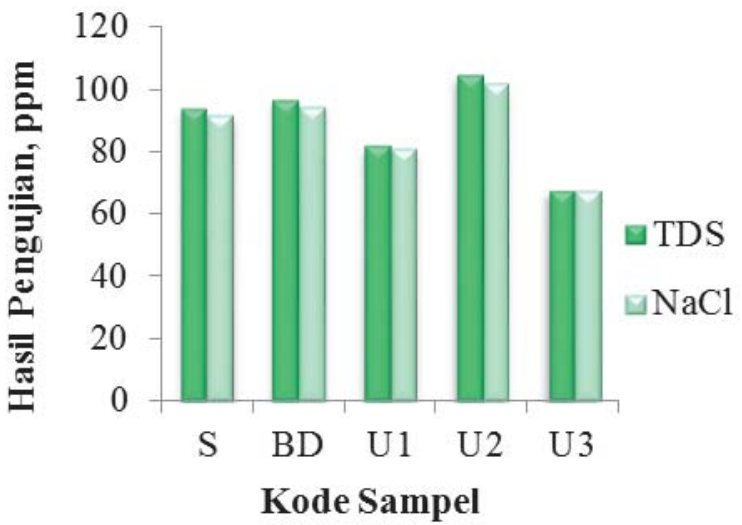

Gambar 1.Hubungan TDS dan Salinitas akumulasi air hujan.

\section{Penentuan $\mathrm{Pb}$ Terlarut dengan Metode Kalibrasi}

Metode kalibrasi merupakan metode umum yang digunakan untuk menentukan konsentrasi karena cocok untuk menganalisis banyak sampel secara cepat. Metode ini menggunakan seri larutan standar dengan konsentrasi tertentu (García dan Báez, 2012).

Hasil absorbansi larutan standar kalibrasi $\mathrm{Pb}$ dapat dilihat dalam Tabel 2. Absorbansi blanko keluaran alat tidak sama dengan nol, sehingga semua absorbansi larutan standar harus dikurangi dengan absorbansi blanko.

Absorbansi larutan standar kalibrasi $\mathrm{Pb}$ dengan diplotkan terhadap seri konsentrasi larutan standar $\mathrm{Pb}$ dalam bentuk kurva kalibrasi standar $\mathrm{Pb}$ Gambar 2.

Kurva kalibrasi standar $\mathrm{Pb}$ memberikan persamaan garis $\mathrm{y}=7,04 \cdot 10-3 \mathrm{x}-4,30 \cdot 10-4$. Analisis regresi linear menunjukkan korelasi $(\mathrm{R})$ sebesar 0,957 dan koefisien determinasi (R2) 0,916. Nilai korelasi (R) digunakan untuk mengetahui hubungan antara
Tabel 2. Absorbansi Larutan Standar $\mathbf{P b}$

\begin{tabular}{ccc|}
$\begin{array}{c}\text { Konsentrasi } \mathrm{Pb} \\
(\mathrm{mg} / \mathrm{L})\end{array}$ & Abs & Abs 0 \\
0 & $-0,000090$ & 0,000000 \\
0,1 & 0,000361 & 0,000451 \\
0,2 & 0,000849 & 0,000939 \\
0,4 & 0,001554 & 0,001644 \\
0,6 & 0,002960 & 0,003050 \\
0,8 & 0,006026 & 0,006116 \\
\hline
\end{tabular}

Abs: absorbansi keluaran alat Abs 0: absorbansi setelah dikurangi absorbansi blanko

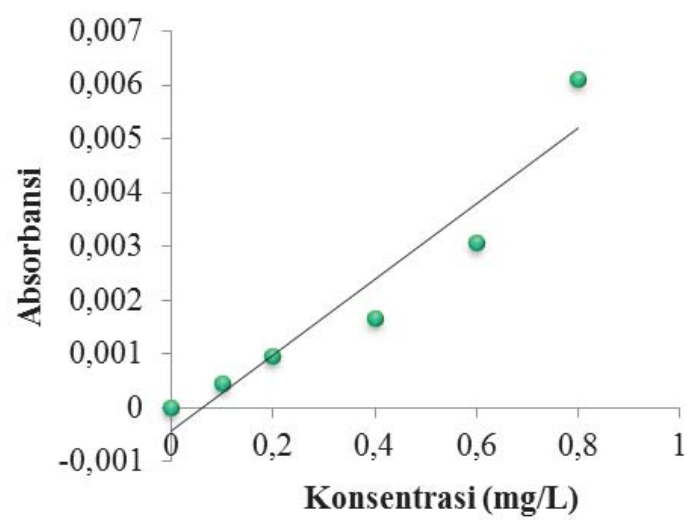

Gambar 2. Kurva Kalibrasi Standar $\mathrm{Pb}$

konsentrasi dengan absorbansi, sementara koefisien determinasi (R2) menunjukkan kedekatan garis regresi linear dengan titik data sebenarnya.

\section{Penentuan LoD dan LoQ}

Limit deteksi (Limit of Detection, LoD) menunjukkan batas konsentrasi terkecil analit yang dapat terdeteksi dalam sampel disertai estimasi bias dan ketidakpresisian pada konsentrasi analit yang sangat kecil (Armbruster dan Pry, 2008). Limit deteksi ditentukan melalui garis regresi linear kurva kalibrasi melalui persamaan $\operatorname{LoD}=(3 \mathrm{sy} / \mathrm{x}) /$ slope, dengan 
Tabel 3. Standar Deviasi Residual

\begin{tabular}{|c|c|c|c|}
\hline$x i$ & yi & $\hat{y} i$ & (yi-ŷi)2 \\
\hline 0,0 & 0,0 & $-4,30.10-4$ & $1,85.10-7$ \\
\hline 0,1 & $4,5.10-4$ & $2,74.10-4$ & $3,14.10-8$ \\
\hline 0,2 & $9,4.10-4$ & $9,78.10-4$ & $1,49.10-9$ \\
\hline 0,4 & $1,64.10-3$ & $2,38.10-3$ & $5,50.10-7$ \\
\hline 0,6 & $3,05.10-3$ & $3,79.10-3$ & $5,52.10-7$ \\
\hline \multirow[t]{2}{*}{0,8} & $6,12 \cdot 10-3$ & $5,20.10-3$ & $8,38.10-7$ \\
\hline & & Jumlah & $2,16.10-6$ \\
\hline
\end{tabular}

sy/x adalah standar deviasi residual (Harmita, 2004). Nilai faktor 3 merupakan rekomendasi IUPAC sesuai tingkat kepercayaan 90\% (Thomsen dkk., 2003).

Standar deviasi residual vang diperoleh dari persamaan $\mathrm{sy} / \mathrm{x}=\sqrt{\sum(y i-\widehat{y i})^{2} \cdot(n-2)^{-1}}$ adalah 7,30.10-4. Limit deteksi pengukuran sesuai persamaan kurva kalibrasi standar $\mathrm{Pb}$ dengan slope 7,04.10-3 adalah 0,3130 mg/L.

Limit kuantitasi (LoQ) ditentukan dari persamaan LoQ $=(10 s y / x) /$ slope. Limit kuantitasi menunjukkan kuantitasi konsentrasi terendah analit yang pasti terdeteksi secara presisi dan akurasi. Limit kuantitasi (LoQ) sesuai persamaan kurva kalibrasi standar $\mathrm{Pb}$ adalah 1,0371 $\mathrm{mg} / \mathrm{L}$.

\section{Penentuan $\mathrm{Pb}$ Terlarut dengan Metode Adisi Standar}

Metode adisi standar adalah salah satu metode standardisasi yang dapat digunakan untuk menentukan konsentrasi sampel. Larutan standar adisi dibuat dengan cara menambahkan larutan standar ke dalam sampel (García dan Báez, 2012). Sinyal analitik seri larutan adisi standar diplotkan terhadap konsentrasi sehingga diperoleh persamaan linear $\mathrm{Y}=\mathrm{bX}+$ yintersep. Nilai xintersep ( $\mathrm{x}$ saat $\mathrm{y}=$ 0) dinyatakan sebagai xintersep $=-\mathrm{CAVo} / \mathrm{Vf}$, dengan volume sampel yang ditambahkan Vo dan volume akhir larutan standar adisi Vf, sehingga konsentrasi analit CA dapat ditentukan.

Salah satu contoh kurva adisi standar ditunjukkan dalam Gambar 3. Larutan standar adisi $0 \mathrm{mg} / \mathrm{L}$ memberikan respon serapan (absorbansi > 0) karena larutan tersebut telah mengandung analit sampel.

Pengukuran sampel S, BD, U1, U2, dan U3 secara adisi standar dengan pengulangan lima kali

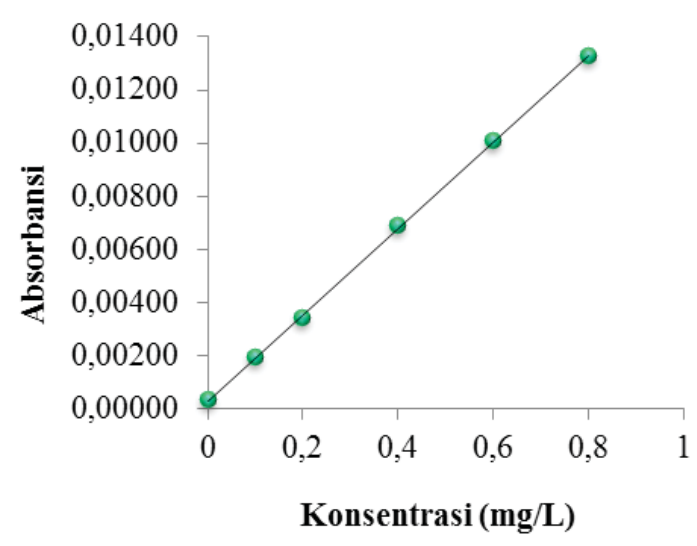

Gambar 3. Kurva Adisi Standar Pb Sampel AU22

memberikan persamaan regresi yang telah memenuhi syarat korelasi minimal SNI 6989.8:2009 ( $\geq 0,995)$, kecuali sampel kode AS. Persamaan regresi yang diperoleh digunakan untuk menentukan xintersep, yaitu nilai $\mathrm{x}$ pada $\mathrm{y}=0$. Konsentrasi analit ditentukan dari nilai xintersep dikalikan faktor pengenceran 10 kali.

\section{Perbandingan Linearitas Kurva Kalibrasi dan} Adisi Standar

Harmita (2004) memaparkan bahwa kemampuan metode analisis untuk memberikan respon yang proporsional terhadap konsentrasi analit dapat dinyatakan dalam linearitas. Linearitas dapat diketahui dari koefisien korelasi kurva.

Kurva kalibrasi standar $\mathrm{Pb}$ sesuai Gambar 2 memberikan korelasi (R) 0,957 tidak memenuhi nilai korelasi minimal SNI 6989.8:2009 ( $\mathrm{R} \geq 0$,995), tetapi masih dapat diterima secara statistik $(\mathrm{R}>0,950)$. Hal ini disebabkan karena sensitivitas metode yang rendah (slope kurva kalibrasi 0,007039) dengan LoD yang tinggi $(0,3130 \mathrm{mg} / \mathrm{L})$ sehingga alat tidak mampu mendeteksi kadar timbal yang sangat rendah secara akurat.

Di sisi lain, nilai korelasi semua kurva adisi standar $\geq 0,995$ telah memenuhi syarat korelasi regresi linear SNI 6989.8:2009, kecuali kurva adisi sampel kode AS. Penambahan analit sampel dalam larutan standar timbal menyebabkan konsentrasi timbal dalam larutan standar bertambah sehingga sinyal yang terukur juga bertambah. Hal ini menyebabkan sensitivitas metode adisi standar lebih baik daripada 
sensitivitas metode kalibrasi. Inilah keunggulan metode adisi standar karena mampu menentukan kadar analit yang sangat rendah.

\section{Perbandingan Hasil Metode Kalibrasi dan Adisi Standar}

Tabel 4 menunjukkan hasil penentuan kadar timbal terlarut dalam sampel air kode S, BD, U1, U2, dan U3 secara metode kalibrasi dan adisi standar. Kedua metode memberikan hasil yang berbeda sehingga tidak diperlukan uji statistika. Hasil kadar timbal terlarut sesuai metode kalibrasi lebih besar daripada hasil metode adisi standar. Namun, kedua hasil tersebut masih memenuhi baku mutu limbah cair golongan II sesuai KEPMENLH Nomor 51 tahun 1995 (kadar timbal < $1 \mathrm{mg} / \mathrm{L}$ ).

\section{Hasil Penentuan Pb Terlarut oleh LPPT UGM}

Parameter timbal terlarut dalam sampel air bak kontrol Candi Borobudur juga diujikan di Laboratorium Penelitian dan Pengujian Universitas Gadjah Mada (LPPT UGM). Pengujian ini dilakukan sebagai pembanding terhadap hasil pengujian timbal terlarut yang dilakukan di BKB.

Pengujian timbal terlarut oleh LPPT UGM dilakukan dengan metode kalibrasi secara SSA-Nyala dengan seri larutan standar $\mathrm{Pb} 0,0 ; 0,1 ; 0,2 ; 0,4 ; 0,6$; $0,8 \mathrm{dan} 1,0 \mathrm{mg} / \mathrm{L}$. Hasil pengukuran larutan standar Tabel 4. Konsentrasi Pb Terlarut Sesuai Metode Kalibrasi
dan Adisi Standar

\begin{tabular}{|c|c|c|}
\hline \multirow[t]{2}{*}{ Kode Sampel } & \multicolumn{2}{|c|}{ Rerata Konsentrasi $\mathrm{Pb}$ (mg/L) } \\
\hline & Kalibrasi & Adisi Standar \\
\hline S & 0,1943 & 0,1628 \\
\hline BD & 0,2492 & 0,0591 \\
\hline U1 & 0,3915 & 0,0335 \\
\hline U2 & 0,5336 & 0,0902 \\
\hline U3 & 0,6263 & 0,0460 \\
\hline
\end{tabular}

$\mathrm{LoD}=0,3130 \mathrm{mg} / \mathrm{L}$

Tabel 5. Absorbansi Larutan Standar Pb di LPPT UGM

\begin{tabular}{|cc|}
\hline Konsentrasi $\mathrm{Pb}(\mathrm{mg} / \mathrm{L})$ & Absorbansi \\
\hline 0 & 0,00020 \\
0,1 & 0,00109 \\
\hline 0,2 & 0,00208 \\
\hline 0,4 & 0,00371 \\
\hline 0,6 & 0,00710 \\
\hline 0,8 & 0,01026 \\
\hline
\end{tabular}

Tabel 6. Konsentrasi Pb Terlarut oleh LPPT UGM

$\begin{array}{cc}\text { Kode Sampel } & \text { Konsentrasi Pb (mg/L) } \\ \text { U1 } & <0,096 \\ \text { U2 } & <0,096 \\ \text { U3 } & <0,096\end{array}$

$\mathrm{LoD}=0,096 \mathrm{mg} / \mathrm{L}$

timbal ditunjukkan dalam Tabel 4. Persamaan regresi yang diperoleh $\mathrm{y}=0,01230 \mathrm{x}-0,0002535$ dengan koefisien korelasi (R) 0,994, koefisien determinasi (R2) 0,987, dan LoD 0,096 mg/L.

Linearitas kurva kalibrasi hasil pengujian di LPPT UGM lebih baik daripada yang dilakukan di BKB. Hal ini dipengaruhi oleh nilai LoD alat SSAnyala LPPT UGM yang lebih kecil daripada LoD alat SSA-nyala BKB. Selain faktor LoD, sensitivitas kedua alat juga berpengaruh terhadap linearitas kurva kalibrasi. Sensitivitas kedua alat ditentukan dari persamaan $\mathrm{S}=0,004 . \mathrm{C} 1 / \mathrm{A} 1$ dengan $\mathrm{C} 10,4 \mathrm{mg} / \mathrm{L}$ dan A1 adalah absorbansi larutan standar $\mathrm{Pb} 0,4 \mathrm{mg} / \mathrm{L}$ masing-masing alat. Hasil perhitungan menunjukkan bahwa alat SSA-nyala LPPT UGM peka terhadap konsentrasi timbal $0,4313 \mathrm{mg} / \mathrm{L}$, sementara SSAnyala BKB peka terhadap konsentrasi timbal 1,0296 $\mathrm{mg} / \mathrm{L}$. Hal ini menunjukkan bahwa alat SSA-nyala LPPT UGM lebih sensitif atau peka daripada alat SSA-nyala di BKB dalam hal pengukuran timbal.

Hasil pengujian sampel U1, U2, dan U3 yang dilakukan oleh LPPT UGM pada Tabel 5 menunjukkan bahwa kadar timbal ketiga sampel berada di bawah LoD $(<0,096 \mathrm{mg} / \mathrm{L})$. Hal ini dapat memperkuat hasil adisi standar yang dilakukan di $\mathrm{BKB}$, terutama untuk sampel kode U1, U2, dan U3. Dalam hal ini, hasil metode adisi standar lebih baik daripada metode kalibrasi untuk penentuan kadar timbal terlarut yang sangat rendah.

\section{Kesimpulan}

Masing-masing metode memberikan kadar timbal terlarut yang berbeda dengan hasil metode kalibrasi yang lebih besar daripada metode adisi standar. Dilihat dari segi hasil dan linearitas kurva, metode adisi standar lebih baik daripada metode kalibrasi untuk penentuan kadar timbal terlarut yang sangat rendah menggunakan alat SSA-Nyala yang kurang sensititf terhadap timbal. 


\section{Daftar Pustaka}

Armbruster, D.A. dan Pry, T., 2008, Limit of Blank, Limit of Detection, and Limit of Quantitation, Clin Biochem Rev, 29, 49-52.

Boniyem, 2013, Verfikasi Metode Uji Penentuan Kandungan Timbal Terlarut pada Sampel Air Filter Layer Candi Borobudur dengan Spektrofotometer Serapan Atom, Laporan PKL, FMIPA, Yogyakarta: Universitas Islam Indonesia (UII).

Harmita, 2004, Petunjuk Pelaksanaan Validasi Metode dan Cara Perhitungannya, Majalah Ilmu Kefarmasian, 3, I, 117-135.

Keputusan Menteri Negara Lingkungan Hidup Nomor 51 Tahun 1995, Baku Mutu Limbah Cair bagi Kegiatan Industri, 23 Oktober 1995, Jakarta.

SNI 6989.8-2009, Air dan Air Limbah - Bagian 8: Cara Uji Timbal (Pb) secara Spektrofotometri Serapan Atom (SSA)-Nyala, 2009, Jakarta: Badan Standardisasi Nasional.
Soekmono, 1983, Pelita Borobudur Laporan Kegiatan Proyek Pemugaran Candi Borobudur Seri A No. 5: Laporan Kerja Proyek Pemugaran Candi Borobudur Tabun Anggaran 1972/1973, Departemen Pendidikan dan Kebudayaan RI.

Thomsen, V., Schatzlein, D., dan Mercuro, D., 2003, Limits of Detection in Spectroscopy, Spectroscopy, 18, 12, 112-114, www. spectroscopyonline.com.

Winarno, S., 1995, Analisa Masalah Air pada Candi Borobudur, Magelang: Departemen Pendidikan dan Kebudayaan Proyek Konservasi Candi Borobudur. 